\title{
Tropical agricultural land management influences on soil microbial communities through its effect on soil organic carbon
}

\author{
Woo Jun Sul ${ }^{\text {a,b,1 }}$, Stella Asuming-Brempong ${ }^{c}$, Qiong Wang ${ }^{\text {a }}$, Dieter M. Tourlousse ${ }^{\mathrm{a}}$, \\ C. Ryan Penton ${ }^{\mathrm{a}, \mathrm{b}}$, Ye Deng ${ }^{\mathrm{d}}$, Jorge L.M. Rodrigues ${ }^{\mathrm{a}, \mathrm{e}}$, Samuel G.K. Adiku ${ }^{\mathrm{c}}$, \\ James W. Jones ${ }^{\mathrm{f}}$, Jizhong Zhou ${ }^{\mathrm{d}}$, James R. Cole ${ }^{\mathrm{a}}$, James M. Tiedje ${ }^{\mathrm{a}, \mathrm{b}, *}$ \\ ${ }^{a}$ Center for Microbial Ecology, Michigan State University, East Lansing, MI 48824, USA \\ ${ }^{\mathrm{b}}$ Plant, Soil and Microbial Sciences, Michigan State University, East Lansing, MI 48824, USA \\ ${ }^{\mathrm{c}}$ Department of Soil Science, College of Agriculture and Consumer Sciences, University of Ghana, Legon, Ghana \\ ${ }^{\mathrm{d}}$ Institute of Environmental Genomics, University of Oklahoma, Norman, OK 73019, USA \\ ${ }^{\mathrm{e}}$ Department of Biology, University of Texas, Arlington, TX 76019, USA \\ ${ }^{\mathrm{f}}$ Agricultural \& Biological Engineering Department, University of Florida, Gainesville, FL 32611, USA
}

\section{A R T I C L E I N F O}

\section{Article history:}

Received 11 February 2013

Received in revised form

1 May 2013

Accepted 10 May 2013

Available online 25 May 2013

\section{Keywords:}

Tropical agricultural practices

Soil organic carbon loss

SSU rRNA genes

Microbial community

Acidobacteria

Bacillales

Pigeon-pea winter-period cultivation

\begin{abstract}
A B S T R A C T
We analyzed the microbial community that developed after 4 years of testing different soil-crop management systems in the savannah-forest transition zone of Eastern Ghana where management systems can rapidly alter stored soil carbon as well as soil fertility. The agricultural managements were: (i) the local practice of fallow regrowth of native elephant grass (Pennisetum purpureum) followed by biomass burning before planting maize in the spring, (ii) the same practice but without burning and the maize receiving mineral nitrogen fertilizer, (iii) a winter crop of a legume, pigeon pea (Cajanus cajan), followed by maize, (iv) vegetation free winter period (bare fallow) followed by maize, and (v) unmanaged elephant grass-shrub vegetation. The mean soil organic carbon $(\mathrm{SOC})$ contents of the soils after 4 years were: $1.29,1.67,1.54,0.80$ and $1.34 \%$, respectively, differences that should affect resources for the microbial community.

From about 290,000 sequences obtained by pyrosequencing the SSU rRNA gene, canonical correspondence analysis showed that SOC was the most important factor that explained differences in microbial community structure among treatments. This analysis as well as phylogenetic ecological network construction indicated that members of the Acidobacteria GP4 and GP6 were more abundant in soils with relatively high SOC whereas Acidobacteria GP1, GP7, and Actinobacteria were more prevalent in soil with lower SOC. Burning of winter fallow vegetation led to an increase in Bacillales, especially those belonging to spore-forming genera. Of the managements, pigeon-pea cultivation during the winter period promoted a higher microbial diversity and also sequestered more SOC, presumably improving soil structure, fertility, and resiliency.
\end{abstract}

(c) 2013 Elsevier Ltd. All rights reserved.

\section{Introduction}

The soil carbon cycle consists of inputs such as plant residues and exudates and outputs such as harvest, carbon dioxide released by microbial decomposition and soil carbon leaching (Trumbore

\footnotetext{
* Corresponding author. Center for Microbial Ecology, 540A Plant and Soil Sciences Building, Michigan State University, East Lansing, MI 48824, USA. Tel.: +1 517 353 0921; fax: +1 5173532917.

E-mail address: tiedjej@msu.edu (J.M. Tiedje).

${ }^{1}$ Present address: Josephine Bay Paul Center for Comparative Molecular Biology and Evolution, 7 MBL Street, Woods Hole, MA 02543, USA.
}

and Czimczik, 2008). The carbon cycle equilibrium is often disturbed by the conversion of natural ecosystems to agriculture, and particularly so in tropical regions. This is mainly due to soil structure disturbances by cultivation and decreased carbon input as a result of typical practices such as burning or crop residue removal. These practices elevate soil organic carbon (SOC) loss by increased rates of decomposition, organic matter oxidation, leaching, and erosion (Lal, 2008). Such management practices typically result in rapid SOC depletion followed by a slower rate of decrease for several decades, before a new SOC steady-state is reached (Scholes et al., 1997). These losses can range between $20 \%$ and $70 \%$ of the original SOC content (Mann, 1986), but can be remediated with the 
use of cover crops and minimum tillage, when the residue is not removed (Mann et al., 2002; Lal et al., 2004). Reduced tillage increases SOC retention through macroaggregate preservation (Grandy and Robertson, 2007), and has been proposed as a primary method for optimizing SOC in fine-textured soils (Chivenge et al., 2007). In recent years, agricultural practices common in tropical regions have been re-evaluated with the goal of gaining benefits from developing a winter fallow crop that would provide food, sequester more soil carbon and improve soil fertility and structure. Since deforestation rates are greater in the tropics than rates of current or historical land use changes in any other region (Houghton, 1994), management practices that preserve soil carbon are expected to have a greater impact on reducing atmospheric $\mathrm{CO}_{2}$, and in doing so, potentially provide monetary incentives for farmers from the developing carbon markets (Sandor et al., 2002).

While much study has focused on the chemical and physical changes to soil due to different cropping systems, the associated shifts in soil microbial community structure and function remain largely unknown. Soil microbial communities are responsible for organic matter mineralization and are thus an integral component of soil productivity and the global carbon and nitrogen cycles. Here, we investigated microbial community shifts using plots under different land managements where the treatment effects on carbon mineralization rates (Adiku et al., 2008), crop yields and soil carbon (Adiku et al., 2009) and on microbial biomass (Asuming-Brempong et al., 2008) are documented. Soil carbon declined from 55 to $19 \%$ and microbial biomass by up to $50 \%$ for the different treatments over the 4-year period. Microbial biomass was also strongly correlated with SOC. Hence, this study provided a unique opportunity to evaluate if different microbial taxa were more sensitive to this major carbon resource shift and to determine if crop and/or management practice altered the microbial community over the relatively short time period. We used pyrosequencing of the SSU rRNA gene (Sogin et al., 2006; Sul et al., 2011) to determine community structure as it provides sufficient information depth so that community responses could be quantified under the contrasting soil management schemes.

\section{Materials and methods}

\subsection{Study sites, experimental design and sampling method}

The research site $(50 \mathrm{~m}$ by $80 \mathrm{~m}$ ) was located at the Kpeve Agricultural Experimental Station (KAES) in the Volta Region, Ghana (coordinates $6^{\circ} 43.15^{\prime} \mathrm{N}, 0^{\circ} 20.45^{\prime} \mathrm{E}$ ). Classified as a savanna to forest transitional zone, the area is dominated by Haplic Lixisols (sandy clay loams), Haplic Acrisols and Leptic Haplic Acrisols. Soil samples were taken as ten sub-samples with a $2.5 \mathrm{~cm}$ diameter corer to $18.5 \mathrm{~cm}$ depth from each of four replicate plots $(10 \mathrm{~m}$ by $10 \mathrm{~m}$ ) in a randomized complete block design of the same annual rotations at the end of the 4th year's maize harvest. In this study, the annual rotations (and notations) were 1) EbM: growth of elephant grass (Pennisetum sp.) in the fallow period (winter, short, dry season) with its residue burned followed by maize crop (native practice), 2) PM: winter pigeon pea (Cajanus cajan) ( $\mathrm{N}_{2}$-fixing) crop, minimal tillage of fallow (winter) period residues followed by maize crop, 3) EfM: winter growth of elephant grass with no burn and followed by fertilized maize crop, 4) BF: bare fallow, i.e. no fallow season plant, followed by maize crop and 5) Eu: regrowth of the native elephant grass-shrub vegetation left unmanaged for 4 years (native condition). Each replicate sample was a homogenized composite of the ten random sub-samples from each replicated plot (Asuming-Brempong et al., 2008), with the exception of Eu, for which the composites consisted of two sub-samples. After collection, soil samples were immediately placed on ice and then stored at $-20^{\circ} \mathrm{C}$ until DNA extraction. Samples were also obtained from agricultural soils in Iowa (IA) and Michigan (MI) to serve as outgroups. These sites had been under no-till management and samples were also collected immediately after maize harvest.

\subsection{SSU rRNA gene pyrosequencing}

Soil DNA was extracted with the Mobio PowerSoil DNA Isolation Kit (Mobio, Carlsbad, CA) and the V4 region of the SSU rRNA gene was amplified using the previously described primer set 1 (Sul et al., 2011). Amplification conditions were as follows: initial incubation for $3 \mathrm{~min}$ at $95^{\circ} \mathrm{C} ; 30$ cycles of $95^{\circ} \mathrm{C}$ for $45 \mathrm{~s}, 57^{\circ} \mathrm{C}$ for $45 \mathrm{~s}$, and $72{ }^{\circ} \mathrm{C}$ for $1 \mathrm{~min}$; and a final $4 \mathrm{~min}$ incubation at $72{ }^{\circ} \mathrm{C}$. Sequencing was performed using the Genome Sequencer FLX System (454 Life Sciences, Bradford, CT), by Michigan State University's Research Technology Support Facility.

\subsection{Pyrosequencing data analysis}

Raw reads were trimmed, quality-filtered, aligned, and clustered (Sul et al., 2011) at 97\% to generate Operational Taxonomic Units (OTUs) using programs from the RDP Pyrosequencing Pipeline (Cole et al., 2009), and assigned to bacterial taxa using the RDP Classifier set at the recommended bootstrap threshold of $50 \%$ (Wang et al., 2007). Bias-corrected Chao1 species richness estimates and Shannon index $\left(\mathrm{H}^{\prime}\right)$ were obtained using EstimateS (www.purl.oclc.org/estimates).

\subsection{Statistical and network analyses}

Canonical correspondence analysis (CCA) and non-metric multidimensional scaling (NMDS) were performed using the $\mathrm{R}$ statistical program ( $R$ Development Core Team, http://www.Rproject.org) running the vegan package (Oksanen et al., 2007). The Random Matrix Theory (RMT)-based network approach (Luo et al., 2006, 2007) was used to construct pMEN (phylogenetic molecular ecological network), which defines the co-occurrence (positive or negative interaction) among OTUs (Zhou et al., 2010). The pMEN construction was performed with OTUs ( $n=1273$ ) present in the non-carbon stressed samples (4 biological replicates of BF, EfM, EbM, and PM). Based on the threshold detected by the RMT method $\left(s_{t}=0.83\right), 476$ OTUs (nodes) remained. The average geodisc distance, average clustering coefficient and modularity of the pMEN were used as values to test the significance of the difference from random networks. All pMEN construction and analyses were performed by a pipeline written in Java and Perl scripts (Zhou et al., 2010). Network graphs were visualized using Cytoscape 2.6.0 software (Cline et al., 2007). Except where otherwise indicated, processing software was written in Java (API v1.5.0) and executed on the Macintosh (OS 10.4) or Linux (2.4.23) operating systems running Java virtual machines from Apple or Sun, respectively. Processed sequences and project are deposited in MG-RAST server (Meyer et al., 2008) under MG-RAST ID:4522002.3-45220024.3 and http:// metagenomics.anl.gov/linkin.cgi? project $=4416$.

\section{Results}

\subsection{Microbial community diversity differed by agricultural management}

The experimental sites were developed to investigate the effect of seven different agricultural managements between 2003 and 2006 (Adiku et al., 2008); we selected four of the most contrasting treatments for our study. Over a 4 -year period, SOC declined under 
all managements from the initial SOC (1.81\%). The greatest loss (56\%) was observed for the BF management, while mean SOC of the EbM, PM, and EfM plots declined by $29 \%, 15 \%$, and $8 \%$, respectively (Table 1). Maize and fallow residues returned to soil were $3 \mathrm{t} \mathrm{ha}^{-1} \mathrm{yr}^{-1}$ (BF), $7 \mathrm{t} \mathrm{ha}^{-1} \mathrm{yr}^{-1}$ (EbM), $15 \mathrm{t} \mathrm{ha}^{-1} \mathrm{yr}^{-1}$ (PM), and $18 \mathrm{t} \mathrm{ha}^{-1} \mathrm{yr}^{-1}$ (EfM) (Adiku et al., 2009). The maize yield in BF plots declined each year after the bare fallow such that in year 4 hardly any maize grew. In the final year of the experiment, EfM had the highest production of maize biomass and maize grain yield, followed by PM and EbM; BF had the lowest (minimal) production (Table 1).

Between 7519 and 12,204 high-quality sequences were obtained for the different samples (Table 1). Rarefaction curves based on the number of OTUs indicated that sampling was, as expected, not fully exhaustive. Bacterial richness (Chao1) was higher in all agricultural plots than in the elephant grass-shrub dominated unmanaged plot (Eu). The pigeon pea - maize rotation (PM) led to significantly higher microbial richness as compared to BF and EfM (ANOVA, $P<0.007$; Tukey's HSD) (Table 1). Also, a significantly higher Shannon index $\left(\mathrm{H}^{\prime}\right)$ was noted for PM as compared to EfM (ANOVA, $P<0.028$; Tukey's HSD), indicating that the former harbored more species with a more even distribution.

\subsection{Taxonomic composition of the soil communities}

The RDP Classifier assigned the sequences to 23 phyla, 57 orders, 149 families, and 490 genera. Irrespective of the rotation practice, seven phyla accounted for $73-86 \%$ of total sequences in a given sample: Acidobacteria, Proteobacteria, Firmicutes, Actinobacteria, Verrucomicrobia, Gemmatimonadetes, and Bacteroidetes (Fig. 1), and are not strikingly different from most of the world's soils (c.f. Janssen, 2006; Fierer et al., 2007). Notably, BF contained more Actinobacteria (ANOVA, $P=0.035$ ) than PM, while PM harboured more Acidobacteria (ANOVA, $P=0.042$ ) than BF (Fig. 1). Furthermore, Acidobacteria Gp6 were predominant in PM as compared to all other managements. Also, residue burning (EbM) contained more Bacillales, especially genera Bacillus $(1.78 \pm 0.89 \% \mathrm{SD}, t$-test, $P<0.01)$ and Sporosarcina $(4.38 \pm 1.19 \%$, SD, $t$-test, $P=0.02)$, than other managements $(0.713 \pm 0.09 \%, \mathrm{SD}, 1.86 \pm 0.24 \%, \mathrm{SD}$, respectively).

\subsection{Structural differences in microbial communities among agricultural managements}

Microbial communities from Ghanaian soil were distinctively different from those in temperate agricultural soils (IA and MI samples), as shown in the NMDS plot (Fig. S1). In order to identify differences among the Ghanaian microbial communities, the NMDS ordination (stress $=20.05$ ), including composites samples (EbMc,

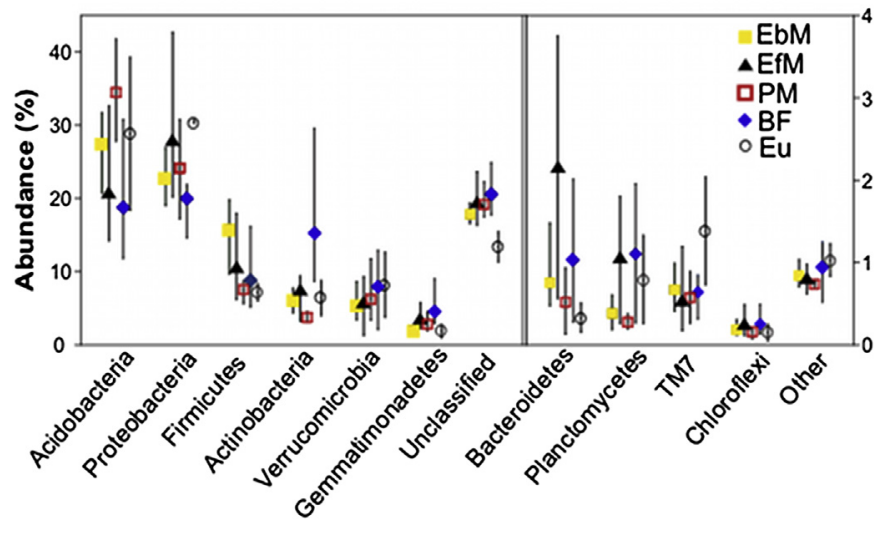

Fig. 1. Phylum-level composition of the microbial communities under the four management and one native conditions. Data are range and mean of four replicates of composite samples. Color identifies the phyla. Note the difference in scale for left and right $y$-axis. (For interpretation of the references to color in this figure legend, the reader is referred to the web version of this article.)

EfMc, BFc, and Euc; the composite of management replicate samples which were obtained by pooling the same amount of DNA from each replicate sample), found segregation among the SOC-reduced $\mathrm{BF}$ and the other four managements (ANOSIM's $r=0.345$, $P<0.001$ ) (data not shown). When the data were limited to the 16 samples (four replicates of each of the four managements), the 155,813 sequences clustered at $97 \%$ yielded 39,546 OTUs. This NMDS ordination (stress $=17.23$ ) also underscored the separation between $\mathrm{BF}$ and the other managements (ANOSIM's $r=0.366$, $P<0.001$ ) (Fig. 2A). When environmental variables (Table 1 ) were fitted onto NMDS ordination, all BF were negatively correlated to both SOC ( $r^{2}=0.41, P=0.032$ based on 999 permutations) and maize biomass ( $r^{2}=0.50, P=0.012$ based on 999 permutations) (Table 2). This suggests that the microbial communities shift primarily in response to SOC content and secondarily to maize biomass, which also likely contributes to SOC. Partial canonical correspondence analysis (pCCA) by SOC further revealed several species that appeared to be influenced by SOC content (Figs. 2B and 3). More specifically, Acidobacteria (Gp1 and Gp7) and subclass Rubrobacteridae, belonging to Actinobacteria, were related to $\mathrm{BF}$ (characterized by lower SOC) whereas Acidobacteria Gp6 and Gp4, as well as Verrucomicrobia subdivision 3 were not related to $\mathrm{BF}$ (Fig. 3).

\subsection{Relationship of modules (networks of OTUs) and SOC by pMENs}

The ecological interaction among OTUs was measured by module-based pMENs. After several iterations, the pMENs defined

Table 1

Summary of relevant site characteristics of plots and pyrosequencing results.

\begin{tabular}{|c|c|c|c|c|c|c|c|c|c|c|}
\hline $\begin{array}{l}\text { Agricultural } \\
\text { management } \\
\text { plots }\end{array}$ & $\operatorname{SOC}^{\mathrm{a}}(\%)$ & $\begin{array}{l}\text { Maize grain } \\
\text { yield }^{\mathrm{b}}\left(\mathrm{t} \mathrm{ha}^{-1}\right)\end{array}$ & $\begin{array}{l}\text { Maize } \\
\text { biomass }^{\mathrm{b}} \\
\left(\mathrm{t} \mathrm{ha}^{-1}\right)\end{array}$ & $\begin{array}{l}\text { Numbers of } \\
\text { sequence }\end{array}$ & Chao1 & $\mathrm{H}^{\prime}$ & $\mathrm{pH}^{\mathrm{a}}$ & $\begin{array}{l}\text { Available } \mathrm{P}^{\mathrm{b}} \\
\left(\mathrm{mg} \mathrm{kg}^{-1}\right)\end{array}$ & $\begin{array}{l}\text { Total nitrogen } \\
\text { (\%) }\end{array}$ & $\begin{array}{l}\text { Microbial biomass } \\
\text { carbon }^{\mathrm{a}}\left(\mathrm{mg} \mathrm{C}-\mathrm{CO}_{2}\right. \\
\mathrm{g}^{-1} \mathrm{dw} \text { soil) }\end{array}$ \\
\hline PM & $1.54( \pm 0.26)$ & 1.48 & 8.12 & $10,869( \pm 1165)$ & $7705( \pm 1129)$ & $7.02( \pm 0.23)$ & $6.43( \pm 0.21)$ & $8.6( \pm 6.9)$ & $0.12( \pm 0.02)$ & $636.8( \pm 96.6)$ \\
\hline EbM & $1.29( \pm 0.26)$ & 1.02 & 6.18 & $9447( \pm 651)$ & $6362( \pm 1028)$ & $6.77( \pm 0.26)$ & $6.68( \pm 0.13)$ & $5.6( \pm 1.9)$ & $0.01( \pm 0.02)$ & $485.0( \pm 102.6)$ \\
\hline EfM & $1.67( \pm 0.22)$ & 2.36 & 9.76 & $9253( \pm 1196)$ & $4747( \pm 550)$ & $6.59( \pm 0.16)$ & $6.42( \pm 0.40)$ & $15.1( \pm 5.0)$ & $0.12( \pm 0.02)$ & $757.5( \pm 189.8)$ \\
\hline $\mathrm{BF}$ & $0.80( \pm 0.14)$ & 0.05 & 0.87 & $9385( \pm 1500)$ & $4966( \pm 1353)$ & $6.42( \pm 0.61)$ & $6.42( \pm 0.13)$ & $5.1( \pm 1.5)$ & $0.06( \pm 0.01)$ & $402.5( \pm 67.6)$ \\
\hline Eu & 1.34 & N.A. & N.A. & $9019( \pm 761)$ & $2320( \pm 504)$ & $5.86( \pm 0.01)$ & 6.7 & N.D. & 0.1 & 858 \\
\hline IA & 2.7 & N.D. & N.D. & 10,564 & 2258 & 6.15 & 5.5 & N.D. & 0.2 & N.D. \\
\hline
\end{tabular}

N.D., not determined.

N.A., not applicable.

a Data were obtained from Asuming-Brempong et al. (2008). SOC of Eu plots were average of $\mathrm{Eu}_{1}$ and $\mathrm{Eu}_{2}$.

b End of experiment year (2006) data obtained from Adiku et al. (2009). 
A

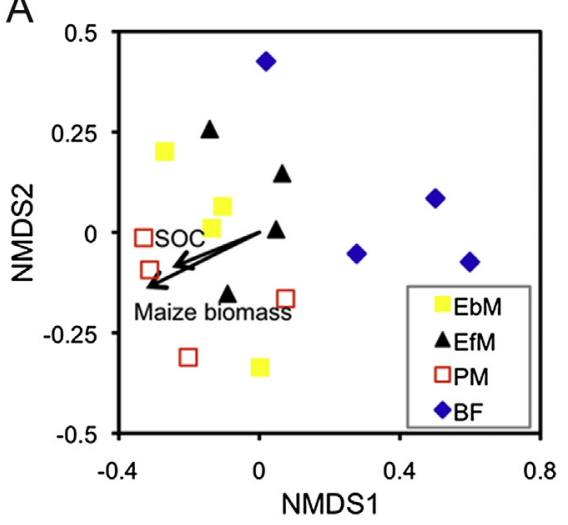

$\mathrm{B}$

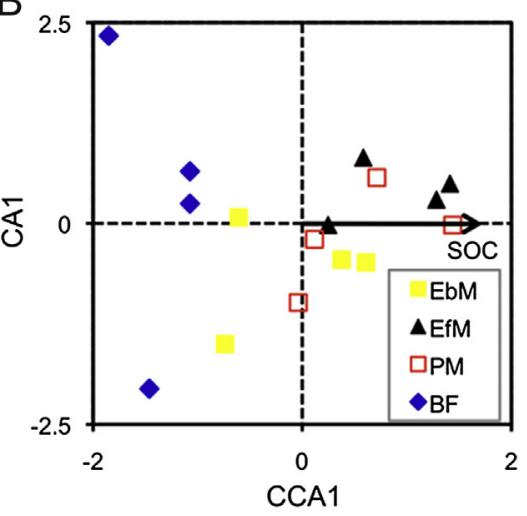

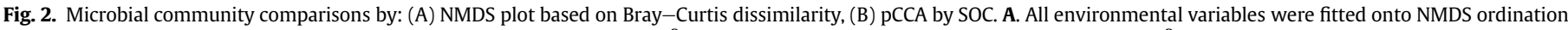

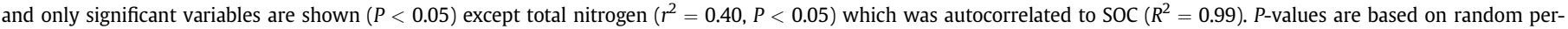
mutations of 50,000. Arrow sizes are scaled by the square root of $r^{2}$. B. The significance of constraints, SOC, in CCA were tested by permutations (pseudo- $F>0.015$ ).

476 OTUs (nodes) for which the average geodisc distance, average clustering coefficient and modularity were significantly different from those of random networks at the applied analysis threshold $\left(s_{t}=0.83\right)$. After further analysis, we obtained 15 highly connected modules that contained more than 5 OTUs (Fig. 4). Pearson correlation between these modules and environmental variables showed that modules 1,3 , and 7 exhibited a significant positive correlation $(P<0.05)$ to either SOC, maize grain yield, or maize biomass, whereas modules 8 and 10 displayed a negative correlation to those parameters and available phosphorus. Interestingly, modules 1 and 7 mostly consisted of Acidobacteria OTUs affiliated to Gp4 and Gp6 (Fig. 5), in agreement with the pCCA analyses.

\section{Discussion}

After four years, microbial communities in Ghanaian soil responded to the different managements with detectable changes in their diversity and composition. The overall microbial community diversity was higher for all agricultural managements than in the elephant grass-shrub dominated unmanaged plot (Eu). Bacterial groups that were responsive to particular treatments were additions to the endogenous community found in Eu. These groups are likely part of the "rare biosphere" in the Eu community but respond to the new selection provided by the new managements. Physical disturbance of the soil under these managements due to plowing, planting, and burning of fallow plants may induce more community dynamics, including resource competition.

In terms of species richness, the lowest diversity was found in $\mathrm{BF}$, which was likely due to very low carbon inputs. Even though fertilizer application led to the highest carbon input due to organic residue deposition (Adiku et al., 2008), microbial diversity was

Table 2

Correlation of environmental factor on the NMDS ordinations.

\begin{tabular}{lll}
\hline Variables & $\begin{array}{l}\text { Squared correlation } \\
\text { coefficient }\left(R^{2}\right)\end{array}$ & $P$ value \\
\hline SOC & 0.41 & 0.028 \\
pH & 0.08 & 0.569 \\
Available P & 0.11 & 0.461 \\
Total nitrogen & 0.40 & 0.031 \\
Microbial biomass & 0.20 & 0.217 \\
Maize grain yield & 0.31 & 0.093 \\
Maize biomass & 0.50 & 0.014 \\
Treatment (binary, BF or non-BFs) & 0.68 & 0.001 \\
\hline
\end{tabular}

$P$ value was calculated based on 999 permutations. relatively lower in the EfM plot, both in terms of richness and evenness. This is likely due to the higher nutrient availability, driving a less metabolically diverse $r$-selected community. Conversely, the PM management sequestered some carbon as woody biomass derived from high lignin content (13-18\%) in pigeon pea. providing more aromatic residues and slower nutrient release, as well as added $\mathrm{N}$ from its $\mathrm{N}_{2}$-fixation capabilities. Based on these results, and supported by previous T-RFLP analysis (Asuming-Brempong et al., 2008), pigeon pea appears to be an appropriate cover crop for the fallow (winter) period in tropical agricultural systems by fostering a diverse microbial community while also maintaining SOC and supplying nitrogen.

Soil microbial community structure and specific taxa distributions were found to be most affected by SOC. Sequestered carbon appeared to largely influence Actinobacteria and Acidobacteria abundance in soil. The low-SOC BF treatment consistently exhibited the highest abundance of Actinobacteria, mostly of the subclass Rubrobacteridae. Previously isolated bacteria within this subclass, Rubrobacter (Chen et al., 2004) and Thermoleophilum (Yakimov et al., 2003), are resistant to radiation and are found primarily in arid soil, which is consistent with the harsh exposed soil condition due to the meager summer maize crops in last two experimental years (Table 1). It does not appear that all Acidobacteria groups uniformly respond to the same environmental variables, especially SOC. This is not unexpected for this very large, diverse and understudied phylum. Acidobacteria Gp4 and Gp6 were present in higher abundances in the nutrient-enriched plots than Acidobacteria Gp1 and Gp7 (Fig. 3), even though Acidobacteria are thought to be oligotrophs. Network analysis also supported a positive correlation between SOC and modules containing Acidobacteria Gp4 and Gp6. Previously, the abundance of Acidobacteria groups was correlated to soil pH (Jones et al., 2009), with Acidobacteria $\mathrm{Gp} 1$ and $\mathrm{Gp} 3$ abundance largely positively correlated to acidity while Gp4, Gp5, Gp6, and Gp7 correlated to alkalinity when soils within the ranges of $4.5-8.3$ were tested (Rousk et al., 2010). Also, wheat-soybean rotation was associated with the higher Acidobacteria $\mathrm{Gp} 4$ abundance than continuous wheat management while Gp1 abundance was the opposite (Yin et al., 2010). This is also explained by a difference in soil $\mathrm{pH}$ of different crop rotations: wheat-soybean rotation $(\mathrm{pH}=5.5)$ and continuous wheat management $(\mathrm{pH}=4.6-4.7)$. However, our soils were within $\mathrm{pH}$ 6-6.9 (Table 1); as such, pH does not appear to be a significant factor in this study. Our soil exhibits lower SOC than the general range of global SOC, a narrower $\mathrm{pH}$ range and no cold or freezing stresses. Thus, the abundance of Acidobacteria groups in our study can 

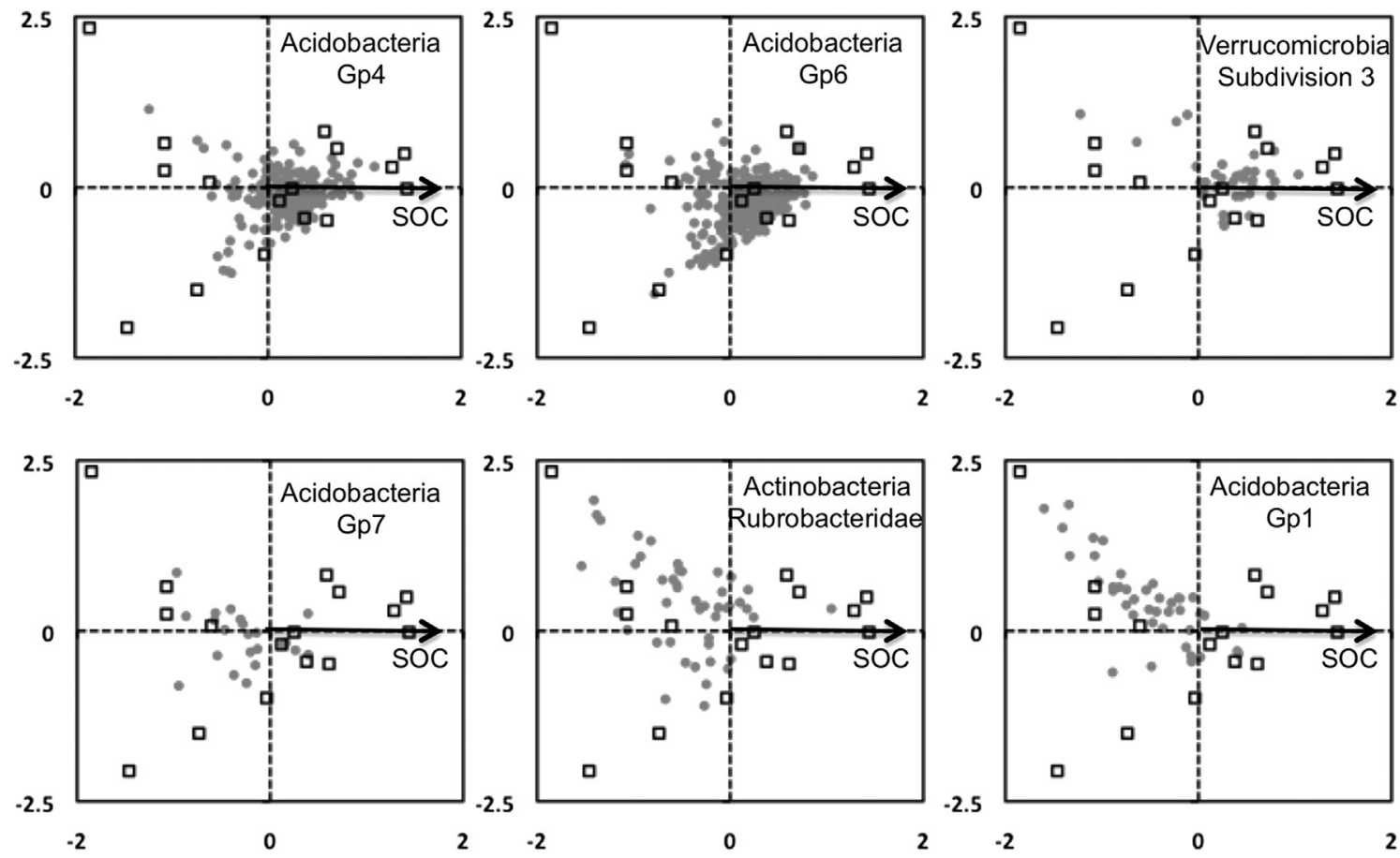

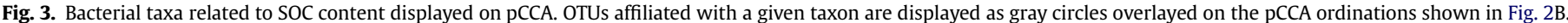
Abundant OTUs (containing more than 10 sequences) in the 16 microbial communities (displayed as empty squares) were displayed.

provide insight into understanding the ecophysiology of the Acidobacteria phylum in low SOC and near neutral pH environments.

Burning of residues produces measured soil temperatures in topical soils of $200-800{ }^{\circ} \mathrm{C}$ at $0.5 \mathrm{~cm}$ and $100-200{ }^{\circ} \mathrm{C}$ at $2.5 \mathrm{~cm}$ depths (Giardina et al., 2000). Soil temperatures of $120{ }^{\circ} \mathrm{C}$ and $250{ }^{\circ} \mathrm{C}$ have been shown to be lethal to $34-80 \%$ and $85-99 \%$, respectively, of the microbial biomass (Giardina et al., 2000). Although temperature was not measured in this study, the higher proportion of Bacillales, especially genera Bacillus and Sporosarcina, in the burned plots (EbM) was notable. It may be due to the heat resistance of these spore-forming bacteria. Sporosarcina spp. not only tolerates high temperature, but also grows at $50{ }^{\circ} \mathrm{C}$ (Kämpfer et al., 2010). Our core samples were taken over the top $18.5 \mathrm{~cm}$ so the effect of burning was probably muted by the populations at the lower depths unaffected by temperature. The fact that we could see any effect, however, suggests that burning was selective on the resulting community.

Carbon is the key resource supporting most terrestrial microbial communities. Its decline due to cultivated agriculture in temperate region soils is much slower. In tropical systems, however, the continuously warmer temperatures and where moisture is sufficient and perhaps cultivation occurs, there is a faster loss of organic carbon. In this study the soil carbon declined by up to 55\% in only 4 years. This loss plus the lack of significant annual resupply of available carbon by plants especially in years 3 and 4 of the bare fallow treatment would be expected to be a major perturbation to the microbial community, and did show a loss of $50 \%$ of the microbial biomass (Asuming-Brempong et al., 2008). We found a

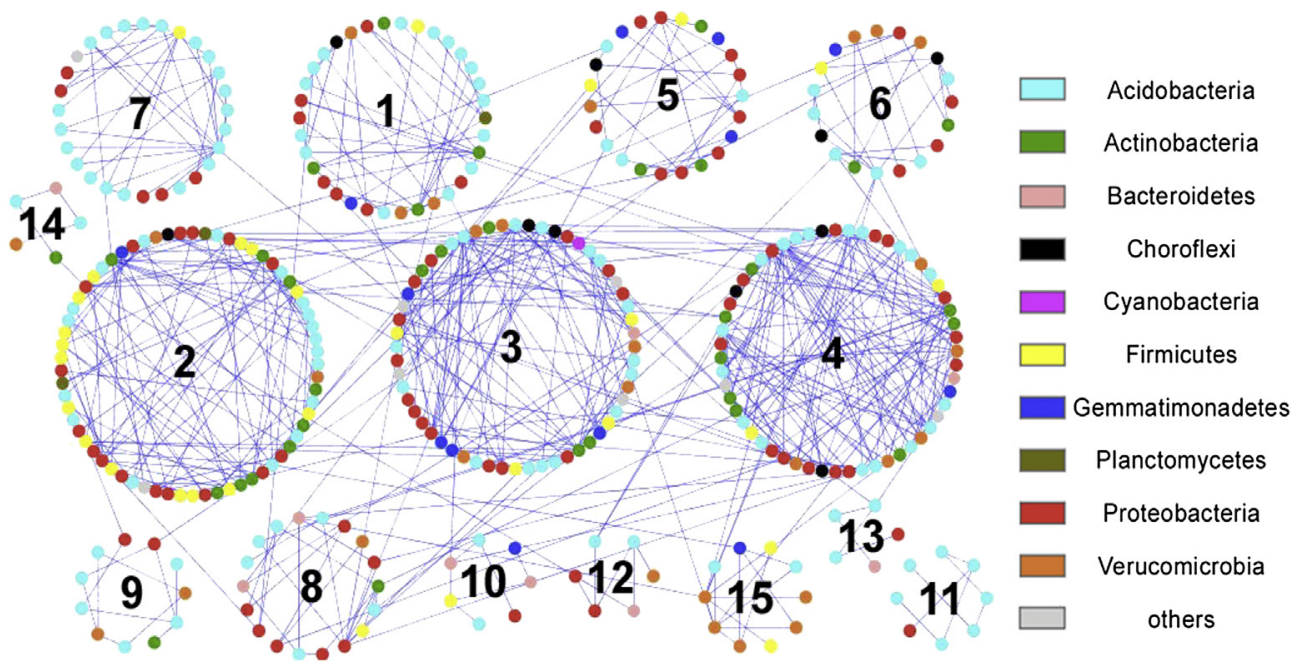

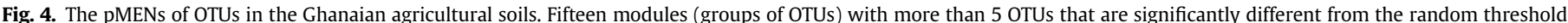

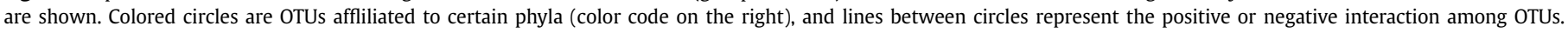
Numbering of modules is random. (For interpretation of the references to color in this figure legend, the reader is referred to the web version of this article.) 


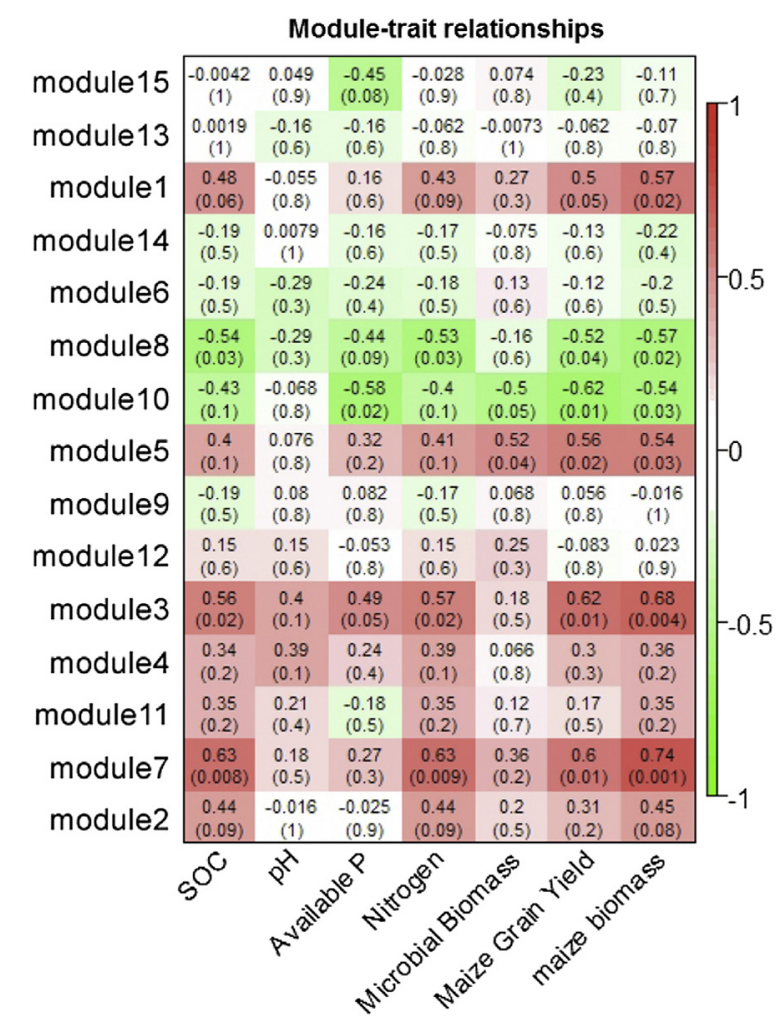

Fig. 5. Pearson correlations between modules and environmental variables (Table 1). Module number is the same as in Fig. 4. Values of Pearson correlations are colored by red as positive and green as negative. Numbers in parenthesis represent the significance ( $P$-value) of the Pearson correlations. (For interpretation of the references to color in this figure legend, the reader is referred to the web version of this article.)

significant but not dramatic change in the microbial community structure, suggesting that the community as a whole is rather resistant to this even more extreme decline in its food sources.

\section{Acknowledgments}

This work was supported by grants from U.S. Department of Energy Office of Science, Biological and Environmental Research (DE-FG02-99ER62848, DE-FG02-04ER63933); National Science Foundation (DBI-0328255); and the U.S. Department of Agriculture (NRI 2008-35107-04542)

\section{Appendix A. Supplementary data}

Supplementary data related to this article can be found at http:// dx.doi.org/10.1016/j.soilbio.2013.05.007.

\section{References}

Adiku, S.G.K., Narh, S., Jones, J.W., Laryea, K.B., Dowuona, G.N., 2008. Short-term effects of crop rotation, residue management, and soil water on carbon mineralization in a tropical cropping system. Plant and Soil 311, 29-38.

Adiku, S.G.K., Jones, J.W., Kumaga, F.K., Tonyigah, A., 2009. Effects of crop rotation and fallow residue management on maize growth, yield and soil carbon in a savannah-forest transition zone of Ghana. Journal of Agricultural Science 147, 313-322.

Asuming-Brempong, S., Gantner, S., Adiku, S.G.K., Archer, G., Edusei, V., Tiedje, J.M., 2008. Changes in the biodiversity of microbial populations in tropical soils under different fallow treatments. Soil Biology and Biochemistry 40, 2811-2818.

Chen, M.Y., Wu, S.H., Lin, G.H., Lu, C.P., Lin, Y.T., Chang, W.C., Tsay, S.S., 2004. Rubrobacter taiwanensis sp. nov., a novel thermophilic, radiation-resistant species isolated from hot springs. International Journal of Systematic and Evolutionary Microbiology 54, 1849-1855.
Chivenge, P.P., Murwira, H.K., Giller, K.E., Mapfumo, P., Six, J., 2007. Long-term impact of reduced tillage and residue management on soil carbon stabilization: implications for conservation agriculture on contrasting soils. Soil and Tillage Research 94, 328-337.

Cline, M.S., Smoot, M., Cerami, E., Kuchinsky, A., Landys, N., Workman, C., Christmas, R., Avila-Campilo, I., Creech, M., Gross, B., Hanspers, K., Isserlin, R. Kelley, R., Killcoyne, S., Lotia, S., Maere, S., Morris, J., Ono, K., Pavlovic, V., Pico, A.R., Vailaya, A., Wang, P.L., Adler, A., Conklin, B.R., Hood, L., Kuiper, M., Sander, C., Schmulevich, I., Schwikowski, B., Warner, G.J., Ideker, T., Bader, G.D., 2007. Integration of biological networks and gene expression data using Cytoscape. Nature Protocols 2, 2366-2382.

Cole, J.R., Wang, Q., Cardenas, E., Fish, J., Chai, B., Farris, R.J., Kulam-SyedMohideen, A.S., McGarrell, D.M., Marsh, T., Garrity, G.M., Tiedje, J.M., 2009. The Ribosomal Database Project: improved alignments and new tools for rRNA analysis. Nucleic Acids Research 37, D141-D145.

Fierer, N., Bradford, M.A., Jackson, R.B., 2007. Toward an ecological classification of soil bacteria. Ecology 88, 1354-1364.

Giardina, C.P., Sandford, R.L., Døkersmith, I.C., Jaramillo, V.J., 2000. The effects of slash burning on ecosystem nutrients during the land preparation phase of shifting cultivation. Plant and Soil 220, 247-260.

Grandy, A.S., Robertson, G.P., 2007. Land-use intensity effects on soil organic carbon accumulation rates and mechanisms. Ecosystems 10, 58-73.

Houghton, R.A., 1994. The worldwide extent of land use change. BioScience 44 305-313.

Janssen, P.H., 2006. Identifying the dominant soil bacterial taxa in libraries of $16 \mathrm{~S}$ rRNA and 16S rRNA genes. Applied and Environmental Microbiology 72, 17191728.

Jones, R.T., Robeson, M.S., Lauber, C.L., Hamady, M., Knight, R., Fierer, N., 2009. A comprehensive survey of soil acidobacterial diversity using pyrosequencing and clone library analyses. The ISME Journal 3, 442-453.

Kämpfer, P., Falsen, E., Lodders, N., Schumann, P., 2010. Sporosarcina contaminans sp. nov. and Sporosarcina thermotolerans sp. nov., two endospore-forming species. International Journal of Systematic and Evolutionary Microbiology 60, 1353-1357.

Lal, R., 2008. Carbon sequestration. Philosophical Transactions of the Royal Society B: Biological Sciences 363, 815-830.

Lal, R., Griffin, M., Apt, J., Lave, L., Morgan, M.G., 2004. Ecology. Managing soil carbon. Science 304, 393.

Luo, F., Zhong, J.X., Yang, Y.F., Scheuermann, R.H., Zhou, J.Z., 2006. Application of random matrix theory to biological networks. Physics Letters A 357, 420-423.

Luo, F., Yang, Y., Zhong, J., Gao, H., Khan, L., Thompson, D.K., Zhou, J., 2007. Constructing gene co-expression networks and predicting functions of unknown genes by random matrix theory. BMC Bioinformatics 8, 299.

Mann, L.K., 1986. Changes in soil carbon storage after cultivation. Soil Science 142 279-288.

Mann, L., Tolbert, V., Cushman, J., 2002. Potential environmental effects of corn (Zea mays L.) stover removal with emphasis on soil organic matter and erosion. Agriculture, Ecosystems \& Environment 89, 149-166.

Meyer, F., Paarmann, D., D’Souza, M., Olson, R., Glass, E.M., Kubal, M., Paczian, T., Rodriguez, A., Stevens, R., Wilke, A., Wilkening, J., Edwards, R.A., 2008. The metagenomics RAST server - a public resource for the automatic phylogenetic and functional analysis of metagenomes. BMC Bioinformatics 9, 386.

Oksanen, J., Kindt, R., Legendre, P., O'Hara, R.B., 2007. Vegan: Community Ecology Package Version 1.8-6. http://cran.r-project.org/.

Rousk, J., Bååth, E., Brookes, P.C., Lauber, C.L., Lozupone, C., Caporaso, J.G., Knight, R. Fierer, N., 2010. Soil bacterial and fungal communities across a $\mathrm{pH}$ gradient in an arable soil. The ISME Journal 4, 1340-1351.

Sandor, R., Walsh, M., Marques, R., 2002. Greenhouse-gas-trading markets. Philosophical Transactions of the Royal Society A: Mathematical, Physical, and Engineering Sciences 360, 1889-1900.

Scholes, M.C., Powlson, D., Tian, G.L., 1997. Input control of organic matter dynamics. Geoderma 79, 25-47.

Sogin, M.L., Morrison, H.G., Huber, J.A., Mark Welch, D., Huse, S.M., Neal, P.R. Arrieta, J.M., Herndl, G.J., 2006. Microbial diversity in the deep sea and the underexplored "rare biosphere". Proceedings of the National Academy of Sciences USA 103, 12115-12120.

Sul, W.J., Cole, J.R., Jesus, E.C., Wang, Q., Farris, R., Fish, J.A., Tiedje, J.M., 2011. Bacterial community comparisons by taxonomy-supervised analysis independent of sequence alignment and clustering. Proceedings of the National Academy of Sciences USA 108, 14637-14642.

Trumbore, S.E., Czimczik, C.I., 2008. Geology. An uncertain future for soil carbon. Science 321, 1455-1456.

Wang, Q., Garrity, G.M., Tiedje, J.M., Cole, J.R., 2007. Naive Bayesian classifier for rapid assignment of rRNA sequences into the new bacterial taxonomy. Applied and Environmental Microbiology 73, 5261-5267.

Yakimov, M.M., Lünsdorf, H., Golyshin, P.N., 2003. Thermoleophilum album and Thermoleophilum minutum are culturable representatives of group 2 of the Rubrobacteridae (Actinobacteria). International Journal of Systematic and Evolutionary Microbiology 53, 377-380.

Yin, C., Jones, K., Peterson, D., Garrett, K., Hulbert, S., Schroeder, K., Paulitz, T., 2010. Members of soil bacterial communities sensitive to tillage and crop rotation. Soil Biology and Biochemistry 42, 2111-2118.

Zhou, J., Deng, Y., Luo, F., He, Z., Tu, Q., Zhi, X., 2010. Functional molecular ecological networks. mBio 1, e00169-10. 